\title{
LA CORRUPCIÓN DE LOS FUNCIONARIOS PÚBLICOS EN TIEMPOS DEL CORONAVIRUS
}

\section{THE CORRUPTION OF PUBLIC OFFICIALS IN TIMES OF THE CORONAVIRUS}

José Julio Goicochea Elías

* Doctor en Derecho, docente de Derecho Penal de pre y posgrado en universidades nacionales y privadas en el Perú

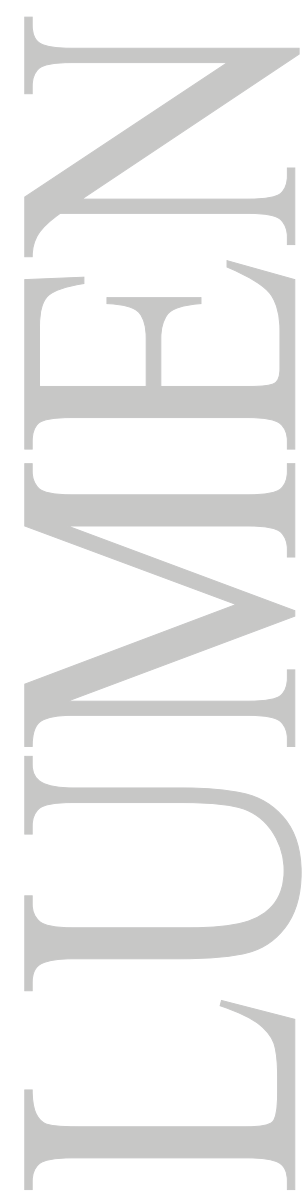




\title{
LA CORRUPCIÓN DE LOS FUNCIONARIOS PÚBLICOS EN TIEMPOS DEL CORONAVIRUS
}

\author{
THE CORRUPTION OF PUBLIC OFFICIALS IN TIMES \\ OF THE CORONAVIRUS
}

José Julio Goicochea Elías

\begin{abstract}
RESUMEN:
La pandemia del coronavirus que actualmente viene flagelando a la humanidad ha conseguido llevar nuestra capacidad de sorpresa a límites insospechados; por un lado, observamos a través de los medios de comunicación masiva a Oficiales de alto rango de la Policía Nacional del Perú comprando a precios exorbitantes productos que no reúnen estándares de calidad (mascarillas, guantes etc.) para entregárselos a sus colegas que valerosamente arriesgan sus vidas para cuidar la nuestra. También a alcaldes regionales, provinciales y distritales haciendo acopio propio de artículos de primera necesidad; $y$, a magistrados que en audiencias virtuales siguen conociendo procesos derivados de actos de corrupción cometidos por jueces que, desdiciendo de conceptos elementales de ética y moral, se aprovecharon de su cargo para hacer tabla rasa del derecho y la justicia. Está demás señalar que la responsabilidad de estos malos servidores se agrava de manera superlativa por la enfermedad que nos viene azotando.
\end{abstract}

\section{PALABRAS CLAVE:}

Funcionario Público, Corrupción. Pandemia, Derecho.

\begin{abstract}
:
The coronavirus pandemic that is currently scourging humanity has managed to take our capacity for surprise to unsuspected limits: on the one hand, we observe through the mass media high- ranking officers of the Peruvian National Police buying products at exorbitant prices that they do not meet quality standards (masks, gloves, etc.) to hand over to their colleagues who valiantly risk their life to take care for ours; to provincial and district mayors making their own stock of basic necessities, and also magistrates who in virtual hearings continue to know processes derived from acts of corruption committed by magistrates who, disregarding Elementary concepts of ethics, took advantage of their position to make a clean sweep of the law and justice. It is worth nothing that the responsibility of these bad servers is aggravated in a superlative way by the disease that has plagued us.
\end{abstract}

\section{KEY WORDS:}

Public Official, Corruption, Pandemic, Law

\section{INTRODUCCIÓN}

Podemos señalar, sin temor a equivocarnos, que la corrupción se encuentra enquistada de manera transversal en todo el aparato del Estado, y que las primeras noticias que se tienen de la misma datan del tardío periodo colonial (Quiroz 2016: 49). En la actualidad, se tiene que un significativo porcentaje de funcionarios públicos no han sabido distinguir con sus actos los roles y funciones que verdaderamente les corresponden, alejándose cada vez más de los intereses de la ciudadanía y de la dignidad de la persona humana, conforme lo consagra el artículo 1 de la Constitución Política del Estado; de manera que vienen defraudando las esperanzas que sobre ellos se habían formado los integrantes del grupo social.

Productos sobrevalorados, alimentos que se alejan de su público objetivo y justicia que se le niega al que por ley y derecho le correspondía, son signos inequívocos de que las cosas en la 
administración pública no marchan bien. A ello se suma la incapacidad de los gobiernos locales y regionales para adoptar medidas urgentes y efectivas que puedan paliar los efectos perniciosos de esta pandemia.

La situación se vuelve más trágica si advertimos que la pandemia que nos azota, como cualquier otra catástrofe, no afecta a todos por igual, pues existen personas o grupos en situación de vulnerabilidad, debido a las condiciones económicas, incluyendo la zona de vivienda, edad, raza, género, nivel de ingresos, etc., que determina el riesgo de una comunidad a sufrir una catástrofe (Sumar 2011: 288), sobre todo en esta parte de la región.

Con razón, la Comisión Interamericana de Derechos Humanos, mediante Resolución N 1/2020, adoptada el 10 de abril de 2020 (Pandemia y Derechos Humanos en las Américas), ha sostenido que:

Las Américas es la región más desigual en el planeta, caracterizada por profundas brechas sociales en que la pobreza y la pobreza extrema constituyen un problema transversal a todos los Estados de la región; así como por la falta de precariedad en el acceso al agua potable y al saneamiento; la inseguridad alimentaria, las situaciones de contaminación ambiental y la falta de viviendas o de habitad adecuado. A lo que se suman altas tasas de informalidad laboral y de trabajo e ingresos precarios que afectan a un gran número de personas en la región y que hacen aún más preocupante el impacto socioeconómico del COVID-19.

En ese contexto, los autores compartimos la idea de que, si bien es cierto contamos con un marco legal más que suficiente, el problema no es tanto la norma cuanto los agentes que operan sobre la misma, sumado ello a la poca capacidad de gestión de los gobiernos locales y regionales, las trabas administrativas y burocráticas, así como la situación de vulnerabilidad en la que se encuentran las personas y grupos sociales.

\section{CONTENIDO}

\section{EL TIEMPO QUE NOS TOCA VIVIR}

No resulta descabellado señalar que los grandes responsables de los desastres epidémicos no resultan ser la pólvora y las balas: sino más bien los virus y las bacterias. Hoy, el planeta se encuentra amenazado por un nuevo virus que ha rebasado todo el conocimiento de la medicina. Esta pandemia ha traído como consecuencia directa que a nivel globalizado hayan colapsado los sistemas sanitarios, o al menos ha llegado a un límite (Gestión: 17/05/2020) ${ }^{1}$ Los centros hospitalarios se han visto desbordados en su capacidad por el número alarmante de pacientes y por el poco material humano en relación a los médicos y enfermeros, que vienen ofrendando sus vidas cuidando las nuestras. Seguramente cuando toda esta pesadilla termine, nuestra manera de enfocar el mundo cambie y le demos el sentido que le corresponde a cosas que antes ni siquiera merecían el foco de nuestra atención. Las que nos dejó un tiempo de rosas, como señala la pluma y entona la voz del bardo catalán Joan Manuel Serrat.

El Covid-19 también conocido como Coronavirus se origina en la ciudad de Wuhan (China). Esta enfermedad fue denominada como tal el 11 de febrero del año en curso por Tedros Adhanom, director de la Organización Mundial de la Salud. Los datos que refleja su partida de nacimiento

El vicedecano del Colegio Médico del Perú, Ciro Maguiña, indicó que el sistema de salud del país está a punto de colapsar, debido al incremento de casos graves de COVID-19 tanto en Lima como en otras regiones del país. Así, ha sostenido el médico lo siguiente: "Hemos llegado a un límite real, el colapso está ad portas, no sólo los hospitales, también están llenas las clínicas. Las personas en los seguros tienen que hacer colas, muchos (...) llamas y dicen que no hay espacios. Urgentemente se tiene que habilitar más cámaras." 
se corresponden con tres variables externas: i) corona ii) virus y iii) 19 (referido al año en que se produce el primer brote de la enfermedad). Si bien es verdad, que su origen semántico es sencillo es fácil de comprender, ello no ocurre con el desastre globalizado que su expansión ha traído como consecuencia.

Las consecuencias que ha traído esta enfermedad no se reflejan únicamente en la pérdida de vidas humanas. El efecto sobre las economías ha sido brutal. Los sistemas productivos se han visto paralizados y la pérdida de empleos ha llevado a buscar salidas de emergencia para paliar la crisis: postergación en los cronogramas de pagos y suspensión perfecta de labores son alternativas para aminorar los efectos de la pandemia. Con esta última se suspende la relación laboral: los trabajadores podrán retirar parte de su compensación por tiempo de servicios y parte de sus ahorros en las administradoras de fondo de pensiones.

Los efectos que causa el Covid-19 sobre la salud de las personas son mortales. El virus nos ataca de improviso. No anuncia su llegada. Hasta el momento en que estamos redactando estas líneas no se ha descubierto aun la vacuna que le ponga fin. Las formas en que puede causar efecto son por decir lo menos variopintas: se puede aparecer como un resfriado común hasta alcanzar complicaciones respiratorias de grado avanzado, llegando incluso a darse otras figuras como trombosis falángicas. En los casos de mayor gravedad se hace necesario el internamiento del paciente en un centro hospitalario que cuente con respiradores automáticos. Lamentablemente la expansión pandémica nos ha permitido tomar conciencia de las deficiencias que presenta nuestro sistema hospitalario.

De acuerdo con el Colegio Médico del Perú (CMP), en el país hay 840 médicos contagiados, principalmente en Lima, Iquitos, Trujillo y Pucallpa. De los casos positivos, 43 se encuentran en unidades de cuidados intensivos $(\mathrm{UCl})$ y hay otros cinco que esperan un ventilador mecánico para sobrevivir. "Cada 12 horas ha muerto un médico en mayo, Nos asusta la velocidad con la que están falleciendo nuestros colegas, por eso seguimos pidiendo que no falte oxígeno, medicamentos y ventiladores", asegura Miguel Palacios Celi, decano del Colegio Médico del Perú (CMP). (Diario El Comercio 15/05/2020).

Es bueno señalar que los Hospitales que vienen atendiendo a los pacientes que padecen de Coronavirus son de data antigua; por lo que, se hace necesaria una reformulación del Presupuesto Nacional de la República.

Un repaso a los centros hospitalarios y clínicas que vienen atendiendo los casos de coronavirus nos permite conocer los siguientes detalles:

a) En todo el territorio de la república hay 58 Hospitales y Clínicas que se dedican a la atención de los pacientes que padecen de coronavirus.

b) La mayoría supera los 20 años de antigüedad y han sido construidos y/o remodelados por los presidentes más sancionados por el ojo público según el siguiente detalle: Alan García Pérez (25), Alberto Fujimori Fujimori (21), Manuel Prado Ugarteche (10). Fernando Belaunde Terry (8), Manuel Odría Amoretti (7), Ollanta Humala Tasso (6), Francisco Morales Bermúdez (2) y Juan Velasco Alvarado (1).

c) Durante el gobierno de Alejandro Toledo Manrique la construcción de hospitales y clínicas se vio paralizada por completo.

d) En lo que va de transcurrida de la presente gestión presidencial no se ha atendido el tema de la infraestructura en el sector salud, si bien es cierto que el actual mandatario asume el cargo ante la vacancia del anterior por temas de corrupción y ha tenido que enfrentar esta pandemia, por lo que no cabe ser tan drásticos en lo que le corresponde. 


\section{LA CORRUPCIÓN EN LOS FUNCIONARIOS PÚBLICOS Y SUS EFECTOS EN ÉPOCAS DE PANDEMIA}

A pesar que pueda resultar increíble que en el escenario que actualmente se nos presenta los funcionarios públicos tomen ventaja de sus cargos para cometer actos de corrupción, esta situación se ha presentado en un número significativo de casos. Hemos sido testigos directos a través de información propalada por los medios de comunicación masiva de hechos que demuestran hasta qué punto pueden llegar a ser miserables las conductas del ser humano.

\section{PRELIMINAR NECESARIO}

La corrupción es un fenómeno que no es de ahora. Es de siempre, pervive a través de nuestra historia. Si bien es cierto que no es sencillo determinar cuál ha sido el primer acto de corrupción en la historia, existen algunos antecedentes que nos remontan a la época virreinal, tal como ha hecho referencia Alfonso Quiroz, en su obra Historia de la Corrupción en el Perú, donde señala lo siguiente:

A su arribo a Huancavelica en noviembre de 1758, Ulloa se encontró con una situación crítica en la administración local. Los males incluían fraudes de la recepción y contabilidad de rentas reales, peligrosos estudios técnicos en la explotación de las minas, turbias confabulaciones administrativas y una justicia desvirtuada por el cohecho. (...) Ulloa señaló las corruptelas de las autoridades codiciosas, oficiales reales de Hacienda, mineros y comerciantes que causaban un daño incalculable.

No era la primera vez que Antonio Ulloa (...) denunciaba prácticas corruptas en la administración virreinal peruana. Alrededor de diez años antes de iniciar su gobierno en Huancavelica, Ulloa había escrito el grueso de un informe confidencial (...) que trataba principalmente sobre las disfunciones y abusos administrativos observados durante sus viajes por la América meridional entre 1736 y 1744. (2016, p.47)

Existen hechos que forman parte de nuestra historia y que hasta cierto punto son desconocidos por un gran número de compatriotas. Así, por ejemplo, tenemos el caso de don Ramón Castilla y Marquesado, Presidente de la República en los periodos (1845-1851) y (1855 -1862). Si tomamos como punto de partida que un acto corrupto se enfrenta al interés de la nación, revisemos el siguiente caso donde el futuro mandatario tomo partido por el ejército chileno que invadió territorio nacional en el año de 1838. El historiador Basadre en su Historia de la República del Perú anota lo siguiente:

Ramón Castilla participó en combate vistiendo el uniforme chileno en la Batalla de Yungay el 20 de enero de 1839, a órdenes del general chileno Gonzalo Bulnes, quien había ocupado previamente la ciudad de Lima con sus tropas, es decir que este personaje ayudó a Chile a destruir el Perú junto a la tropa embarcada desde aquel país y que vencieron en Yungay a las tropas peruanas confederadas, al mando del mariscal Andrés de Santa Cruz. Como premio a dicho comportamiento desleal, a Castilla le fue confiado el ministerio de Hacienda por el gobierno de Gamarra, otro personaje, que igualmente vistió el uniforme chileno en aquella oportunidad. (1969, p.167).

Entendemos claramente que, para proceder de dicha forma, es menester superponer los intereses personales a los de la Nación. Lo cierto es que nunca se realizó un juicio político para deslindar responsabilidades, sino que más bien como todos sabemos, luego ocupo el cargo de Presidente de la República en dos periodos.

Por otra parte, nuestros vecinos del sur conmemoran cada 20 de enero la batalla de Yungay. No solamente han levantado un momento recordando la victoria, sino que también ha sido rebautizada 
como Plaza de la Victoria, la plaza principal de Valparaíso. Mientras que, en nuestro país, existen calles, plazas y monumentos que conmemoran a Castilla. ¿Quizás sea duro lo que escribimos, pero cabría preguntarse si realmente queremos combatir la corrupción, los debemos seguir manteniendo?

En sentido contrario, a uno de los autores le tocó vivir un caso singular: de regreso a Lima en el aeropuerto de Ayacucho luego de participar en una audiencia de control formal de acusación en la provincia de Acobamba en el departamento de Huancavelica, estando ya en el avión se da cuenta que una de las pasajeras del vuelo era Maritza Garrido Lecca, bailarina perteneciente al movimiento genocida Sendero Luminoso, quien luego de haber purgado 25 años de prisión efectiva (recuperó su libertad el 11 de septiembre de 2017). En este caso si hubo un juicio público, pero ante el cumplimiento de la condena se abrieron las puertas del penal para ella. La pregunta sería en todo caso: ¿Por qué tenía que viajar precisamente a la ciudad de Ayacucho?

Otro caso de un Presidente de la República envuelto en actos de corrupción. Resulta ser el de Mariano Ignacio Prado.

Se anota lo siguiente en el epílogo de una obra:

Prado fugó en plena Guerra del Pacífico porque defender al país en calidad de presidente del Perú le resultaba contraproducente a sus intereses personales, que estaban en función de sus cuantiosas inversiones en Chile.

Lejos de lo que se ha especulado siempre acerca de la historia del General Prado, éste no comenzó a multiplicar su riqueza a raíz de la fuga durante la guerra (pues en esa época ya era rico), cuando se llevó 3.000 libras (cifra que al cálculo podría llegar hasta los 600.000 dólares) del erario público, sólo como viáticos -ya que los enviados de éste para la supuesta compra de armas ya habían partido a Europa- sin rendir cuenta alguna posteriormente. Sus malversaciones se iniciaron mucho antes, ya que desde su primer gobierno hizo una compra sobrevalorada de los inservibles monitores Manco Cápac y Atahualpa y de la emisión de vales en la revolución de 1865 contra Pezet; (...)

\section{$(\ldots)$}

La guerra benefició a Prado, pues a raíz de dicho triunfo, el nivel de vida en Chile se elevó, lo cual repercutió en el aumento del valor de las inversiones que él tenía allá, de modo tal que dicho caudal multiplicó su valor inicial.

Desde que apareció en la escena política del país. Prado comenzó a tejer importantes redes sociales con los principales personajes políticos chilenos, los que le resultaron sumamente útiles para emprender los diversos negocios que tuvo en Chile, invirtiendo el dinero que sacó del Perú en 1867. (García, 2014)

También es verdad, que si por una parte la imagen que refleja el Poder Judicial es pésima (siendo generosos) -dejando constancia que hay muchos magistrados probos y justos- por culpa de algunos malos magistrados, la imagen del mismo fuera de nuestras fronteras es maravillosa: expresidentes sentenciados, otros con arresto domiciliario, un ex mandatario que se quita la vida disparándose un balazo en la sien para evitar ser llevado a tribunales de justicia, alcaldes y gobernadores procesados y condenados etc., reflejan una actividad proactiva de fiscales y jueces.

No debemos dejar de referirnos al caso de los Cuellos Blancos. Una vergonzosa trama que destapo una red de corrupción que llegaba no solamente a las más altas esferas del Poder Judicial y el Ministerio Público, sino que alcanzaba incluso al fenecido Consejo Nacional de la Magistratura. 
Se destaparon audios donde el contenido rebasaba los índices de nuestra capacidad de asombro: se podía escuchar a un ex magistrado de la Corte Suprema preguntándole a su especialista si el abogado del procesado en un caso de violación sexual con desfloración de himen, estaba solicitando excarcelación o rebaja de condena².

En otro audio se puede escuchar a un ex Presidente de la Corte Superior de Justicia del Callao solicitando favores sexuales a cambio de beneficios laborales; o por ejemplo concertaciones del Fiscal de la Nación con un Presidente de Sala de la Corte Superior pidiendo mano blanda en las denuncias penales que se le habían interpuesto a este último con carácter personal por la investigación de actos de corrupción en los que se encuentra involucrado. Pero ahí no quedaba todo: se costeaban viajes gratuitos con entrada y paquete incluido al Campeonato Mundial de Fútbol disputado en la ciudad de Rusia 2018 con alojamiento en los hoteles donde concentraba la selección peruana.

Y así podríamos citar otros varios ejemplos. Nos encontrábamos ante casos de miseria humana donde la corrupción se había adentrado en lo más profundo de las raíces de uno de los Poderes del Estado: precisamente aquel en el cual los funcionarios que lo integran tenían que administrar justicia a nombre de la nación. Es ahora, que escuchamos pronunciamientos del Ministerio Público señalando que ante la pandemia que estamos sufriendo, los involucrados en este proceso están apelando a discursos emotivos tratando de obtener su libertad. La sociedad en su conjunto debe ejercer como mecanismo de control sobre los responsables para que ello no ocurra, y los involucrados continúen confinados hasta que se determine su responsabilidad o inocencia en un debido proceso.

Por otra parte, es triste por decir lo menos que según datos de Transparencia Internacional a Perú se le otorga el derecho de subir al podio y colgarle la medalla de bronce ${ }^{3}$ : se nos percibe como el tercer país más corrupto a nivel latinoamericano. La presea se la lleva Venezuela con un $50 \%$, la de plata para México con un 34\%, nosotros ahí nomás al acecho con un $30 \%$. Lo real y concreto que esta información tomada del portal del diario Gestión (23/09/2019). Con lo que cuesta conseguir preseas en los estadios deportivos, resulta sorprendente, por decir los menos, lo sencillo que es para algunos funcionarios públicos superar sus propias marcas. Los autores coincidimos en que hay algunas cosas que en nuestra nación ya se han perdido: i) la clase media; ii) la capacidad de ahorro, iii) nuestra capacidad de ahorro y iv) la confianza en algunas de nuestras instituciones tutelares.

\section{Se afirma que:}

En la antigüedad, de todos modos "engrasar las ruedas" era una costumbre tan difundida como hoy y considerada en algún caso ilícita. Las Sagradas Escrituras contienen trazas incontestables de una ética al menos aparentemente diferente respecto a la corriente. En el Antiguo Testamento, jueces y gobernantes dedican su favor a los súbditos más serviciales: hombres astutos y diligentes, dispuestos a dispensar dinero y a inmolar víctimas sacrificiales. El intercambio de favores. Y la necesaria reciprocidad que sustenta, no sólo estaban admitidos sino incluso protegidos de hecho como comportamientos correctos y generalmente aceptados. (Brioschi, 2019)

Para que se produzca un acto de corrupción se requiere la participación de dos sujetos: i) corrupto: quien permite que se le corrompa y ii) corruptor: quien lo corrompe. Cabe acotar que en

2 Todos fuimos testigos del siguiente audio: ¿Cuántos años tiene?... ¿Diez años? ¿Once añitos?... ¿pero está desflorada? Ya...pero ¿Quién le ha hecho esto?... ¿Qué es lo que quieren? ¿Qué le bajen la pena o que lo declaren inocente?

3 También, según el índice de percepción de la corrupción elaborado por Transparencia Internacional, en una escala de 0 a 100, donde 0-9 significa "altamente corrupto" y 90-100 significa "altamente limpio", el Perú tiene un escore de 35 , ocupando además de puesto 105 de un total de 180 países. Esto significa que nuestro país tiene tendencia a niveles más altos de corrupción, lo cual lo ha evidenciado el caso Odebrecht (León 2019: 59-70) 
un gran número de veces se asocia el concepto de corrupción al desarrollo de la parte especial del Código Penal.

(Olano García 2017) señala lo siguiente:

Muchos entienden por corrupción sólo sus consecuencias: Soborno, extorsión, defraudación, tráfico de influencias, peculado, concusión, cohecho, prevaricato; en fin, toda la suma de delitos contra la administración pública que provienen del Código Penal; sin embargo, también para muchos, como lo fue para don Manuel Murillo Toro. "El Código Penal es un perro que sólo muerde a los de ruana".

Es que lamentablemente hemos visto como el derecho penal ha desvirtuado su razón de ser y se ha convertido en un derecho penal de los pobres: i) porque las cárceles están lejos de cumplir su función como centros de readaptación social del delincuente y se asemejan más a campos de concentración, ii) en su gran mayoría están pobladas por internos de escasos recursos económicos y iii) si los presos fallecen (en muchos casos sin sentencia previa por un desproporcionado abuso de las prisiones preventivas) bien muertos están.

Nos encontramos ante un escenario tétrico que configura un caldo de cultivo propicio para la propagación de diversos tipos de enfermedades infecto-contagiosas. Si hasta ahí, el drama sanitario de los penales era enorme, no podemos siquiera imaginar los alcances siderales a los que puede llegar a arribar si le agregamos una epidemia pandémica, como la que hoy nos tiene recluidos en un arresto domiciliario no deseado. En ese orden de ideas, este preámbulo debe servir como conector para relacionarlo con los casos de corrupción que vienen cometiendo los funcionarios públicos en tiempos del coronavirus.

El problema de la corrupción tiene varias aristas.

Se establece un punto de partida importante para entender mejor el problema:

Históricamente la corrupción fue siempre un asunto de funcionarios públicos, o políticos "ímprobos" que se aprovechaban de su cargo para vender funciones públicas o que incluso, en el peor de los casos, extorsionaban a los particulares haciéndoles pagar por los servicios públicos que debían prestar. Esta es la "imagen" de la corrupción que se refleja en los códigos penales europeos del XIX y en cierto modo aún es la "imagen" de la corrupción que pervive entre los ciudadanos (...), la responsabilidad social y moral en los casos de corrupción parece ser exclusiva de los políticos o de los funcionarios públicos. (Nieto M., 2013)

Se observa entonces que la corrupción viene desde antes y siempre ha convivido entre nosotros, constituyendo en realidad un fenómeno amplio y variado, que comprende actividades públicas y privadas. (...) La corruptela comprende el ofrecimiento y la recepción de sobornos, la malversación y la mala asignación de fondos y gastos públicos, la interesada errada de programas y políticas, los escándalos financieros y políticos, los escándalos financieros y políticos, (...) que despiertan la precepción reactiva del público (Quiroz 2013: 30).

Desde un punto de vista jurídico, se viene sosteniendo en la doctrina que la protección contra la corrupción debería configurarse como un auténtico derecho fundamental o como un derecho a vivir en una sociedad libre de corrupción. Así, Jorge León concluye:

En ese sentido, existen principios constitucionales que se concretizan a través de este nuevo derecho. Lo cual nos lleva a señalar, además, que en el Estado democrático no sólo son importantes, el fomento de los derechos que conllevan prestaciones de tipo material, sino 
también la promoción de derechos que impliquen prestaciones estatales de carácter espiritual o éticas. (2019: 59 - 70)

Es importante entonces, concebir a la corrupción como un mal que flagela cualquier sociedad y que es derecho fundamental de las personas vivir en un mundo libre de ese flagelo, de manera que posibilite de manera efectiva la toma de decisiones en situaciones pandémicas tan difíciles como en el que actualmente nos encontramos. O al menos debería repensarse la idea de reconocer dicho derecho como un verdadero derecho fundamental cuyo reconocimiento se incorpore al catálogo de derechos fundamentales contenidos en la Constitución.

\section{LAS PRÁCTICAS CORRUPTAS EN UN ESTADO DE EMERGENCIA}

Habiendo ya realizado algunas referencias históricas sobre la corrupción, es importante tener en claro que puede entenderse por corrupción. Así, en términos generales, Malem Seña, lo define de la siguiente manera:

Por corrupción entenderé aquí aquellas acciones que violan derechos institucionales con el objetivo de obtener beneficios no permitidos por las instituciones a las que se pertenecen o en las cuales de cumple alguna función. Que sean deberes institucionales implica que se violan normas que así los establecen. Y supone, por cierto, que hay individuos que puedan tener determinados deberes que cumplir mientras otros no los tienen. Es decir, existen individuos que por la función que cumplen pueden llegar a corromperse mientras que otros que no desarrollan esa misión no pueden hacerlo. Esto los distingue de los llamados deberes naturales, que deben satisfacer todos los seres humanos con independencia de su estatus personal o jurídico (2018, p.15-29)

La Constitución Política del Estado, en sus artículos 39 y 41, prescribe que todos los funcionarios y trabajadores públicos están al servicio de la Nación. De ahí que el Tribunal Constitucional haya sostenido que los deberes contenidos en el artículo 44 de la Constitución, estos son, defender la soberanía nacional, garantizar la plena vigencia de los derechos humanos, proteger a la población de las amenazas contra su seguridad y promover el bienestar general que se fundamenta en la justicia y en el desarrollo integral y equilibrado de Nación, también se atribuye a los funcionarios y servidores públicos (García 2018, p.33-47)

No obstante ello, en la actualidad, en plena pandemia estamos siendo testigos privilegiados de cómo las autoridades y funcionarios públicos se vienen aprovechando de la situación pandémica; se vienen denunciado e investigando por parte del Ministerio Público hechos de presunta corrupción, en la compra de elementos de protección para la Policía Nacional del Perú. Se ha dispuesto incluso abrir procedimiento administrativo disciplinario y separar del cargo a todos los involucrados. Es más, los hechos descritos motivaron al Presidente de la República Martin Vizcarra no solamente a destituir al Ministro del Interior Carlos Morán, sino a que el nuevo titular del pliego proceda a la recomposición de los altos mandos de las fuerzas policiales.

De otro lado, se tiene noticias que además la Fiscalía viene investigando otros casos de corrupción en pleno Estado de Emergencia a nivel nacional:

El Ministerio Público se encuentra investigando, hasta el momento, unos 76 casos de presunta corrupción a nivel nacional, cometidos durante el estado de emergencia decretado el pasado 15 de marzo para frenar el avance del coronavirus (COVID-19) en el Perú, y relacionados a la entrega de bonos y canastas a la población más vulnerable. (Gestión: 10/04/2020) ${ }^{4}$

4 Según informó Omar Tello Rosales, coordinador de las Fiscalías Especializadas en Delitos de Corrupción de Funcionarios, estas investigaciones se realizan como producto de los actos de supervisión y de las más de mil acciones de prevención dirigidas a los alcaldes y funcionarios municipales. 
Otro titular de los medios de prensa escrita, indica: Entregan víveres vencidos a familias pobres de Tumbes (La República: 01/04/2020)5 También encontramos uno con el siguiente contenido: Entregan azúcar vencida en canastas del municipio de Cocachagra (Prensa Regional: ) La Gerencia Regional de Control de Arequipa detectó un hecho irregular en la entrega de canastas de alimentos a poblaciones vulnerables por la emergencia por el COVID-19, en el distrito de Cocachagra, Provincia de Islay, donde se advirtió la adulteración de la fecha de vencimiento del azúcar.

Las prácticas corruptas glosadas por parte de los distintos funcionarios públicos se presentan en todos los niveles, tanto en gobiernos locales, regionales, en el sistema de justicia, en la Policía, entre otros. Esta situación no es reciente, pues ya se han anotado algunas referencias históricas de la corrupción, y es por ello que nuestro país se encuentra en una ubicación muy lejos de estar lejano a dichas prácticas, tal como se puede visualizar en el cuadro siguiente ${ }^{6}$ :

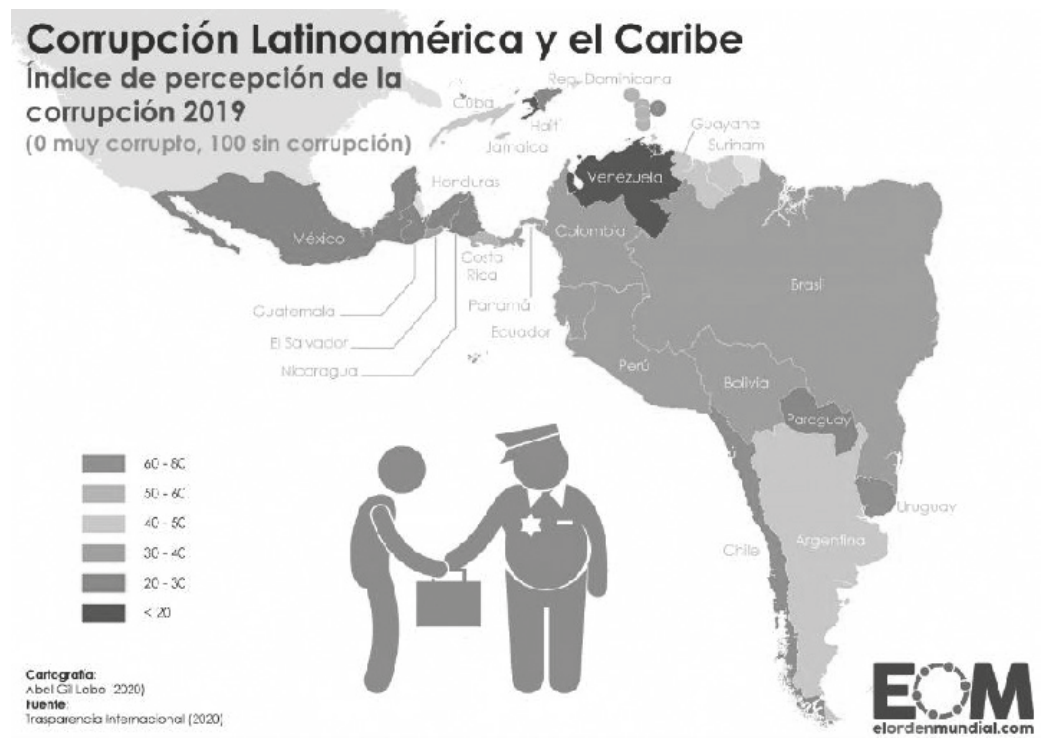

Como las advertidas existen muchas otras prácticas de corruptela; mientras tanto las señales o indicadores perniciosas de corrupción continúan azotando al país, generando un impacto negativo en la satisfacción de los derechos fundamentales, de manera que imposibilitan su pleno goce y ejercicio por parte de sus titulares; sobre todo el derecho a la salud, reconocido por el artículo 7 de la Constitución Política del Estado, según la cual, todos los ciudadanos tenemos derecho a la protección de su salud, la del medio familiar y la de la comunidad así como el deber de contribuir a su promoción y defensa; de manera que podemos sostener, sin temor a equivocarnos, que la corrupción supone siempre una afectación a la dignidad de la persona humana y a los derechos fundamentales que la concretizan.

"Hemos realizado diversas acciones para verificar si los actos denunciados constituyen delitos. Tenemos muchos casos relacionados al bono de 380 soles, a las canastas solidarias que están siendo repartidas en diversas regiones, así como por actos de peculado y cohecho", indicó el fiscal en declaraciones a TV Perú noticias. Según informó Omar Tello Rosales, coordinador de las Fiscalías Especializadas en Delitos de Corrupción de Funcionarios, estas investigaciones se realizan como producto de los actos de supervisión y de las más de mil acciones de prevención dirigidas a los alcaldes y funcionarios municipales. (...) "Hemos realizado diversas acciones para verificar si los actos denunciados constituyen delitos. Tenemos muchos casos relacionados al bono de 380 soles, a las canastas solidarias que están siendo repartidas en diversas regiones, así como por actos de peculado y cohecho", indicó el fiscal en declaraciones a TV Perú noticias.

5 El Gobierno Regional de Tumbes entregó alimentos vencidos a más de cien familias del distrito de Casitas (Contralmirante Villa) como ayuda humanitaria por la emergencia sanitaria que vive el país por el coronavirus. El jefe de la oficina de la Defensoría del Pueblo en Tumbes, Abel Chiroque. exhortó a las autoridades a tener especial cuidado con la entrega de los alimentos de primera necesidad porque podría afectar la salud de la ciudadanía.

6 https://elordenmundial.com/mapas/la-corrupcion-en-america-latina/ 
Debe entenderse, además, que la corrupción se constituye como un instrumento o método para alcanzar objetivos inalcanzables; es el fruto de una decisión racional y como tal es pensada, planificada y ejecutada voluntaria, consciente e intencionalmente, en términos de Malem Seña; y por consiguiente, como toda acción instrumental, la eficacia de la corrupción para ser exitosa es contextual. Esto hace que a pesar de su universalidad haya países o aspectos de la vida social que son más propensos a la venalidad que otros. Entender este aspecto es importante para diseñar medidas de prevención y de represión que sean adecuadas. (Seña, 2018 p.15-29)

Por consiguiente, se puede concluir que, en efecto, la corrupción que nos flagela en plena pandemia reduce las posibilidades de adoptar medidas de solución frente a los infectados que día a día vienen ingresando a los hospitales y centros de salud. En realidad, no son solo los efectos del coronavirus lo que amenaza la vida e integridad de las personas, sino también, muchos otros males como la corrupción, enquistada en la sociedad, y que dificulta e impide a millones de personas tomar medidas básicas de prevención contra la enfermedad, tal como lo ha sostenido la Comisión Interamericana de Derechos Humanos.

Por ello, tal como han anotado los autores, sirve de poco contar con un marco normativo que sancione penalmente las prácticas corruptas si no se tiene la verdadera intención de proscribirla. Ni un buen Código Penal y buenas leyes serán suficientes para combatir la corrupción si no contamos con buenas personas profesionales y autoridades que la apliquen, en tanto ello no ocurra continuarán produciéndose agresiones contra los derechos fundamentales de la persona; y es que se puede afirmar que:

Hoy en día hay una relación jurídica indiscutible entre corrupción y graves violaciones de derechos humanos a pesar que, a nivel internacional, durante muchos años la lucha contra la corrupción y la defensa de los derechos humanos siguieron caminos separados, usando lenguajes y marcos legales distintos. (Lovaton e Indacochea: 71 - 75)

Parece imposible que en medio de una pandemia que ha traído muerte y dolor a muchos hogares, existan malos funcionarios que sin el menor atisbo de preocupación por la vida de sus compatriota -en algunos casos compañeros de profesión- se aprovechen de sus cargos de la manera más miserable en aras de un lucro personal. Esas malas artes, revestidas de un tinte delincuencial deben ser sancionadas de la manera más drástica una vez que cesen los efectos del Covid-19 en juicios públicos, que revestidos de todas las garantías del debido proceso, permitan a los magistrados ejerciendo las reglas de la sana crítica, determinar la responsabilidad o inocencia de los procesados en cada caso concreto.

Es por ello, que incluso el derecho a la protección frente a la corrupción o a vivir en una sociedad libre de corrupción viene configurando un ámbito adecuado para constituirse como un auténtico derecho fundamental, de manera que tal configuración:

(...) debería permitir a cualquier titular de ese derecho: a participar ampliamente y sin restricciones en la planificación, aprobación y ejecución de toda política pública que implique la disposición de recursos presupuestales; a solicitar investigaciones con resultados concretos en un plazo razonable y en que el titular del derecho inclusive por sí mismo pueda participar; a la protección especial y efectiva a las personas que denuncien actos de corrupción, etc. (León 2019: 59-70) ${ }^{7}$

El mismo autor señala que los tiempos actuales son tiempos para el reconocimiento de nuevos derechos fundamentales. Los impulsos para ello son los problemas derivados de la ciencia, la tecnología, las nuevas formas de información y comunicación, pero también la ética, la política y el medio ambiente. Muchos Tribunales Constitucionales y Cortes Supremas en el mundo por esta razón se muestran muy activos en la creación de "nuevos" 
El Código Penal define en su artículo $425^{\circ}$ quienes son aquellos que pueden ser considerados como funcionarios o servidores públicos, señalando entre otros los casos siguientes:

\section{Artículo $425^{\circ}$}

Son funcionarios y servidores públicos:

3. Todo aquel que, independientemente del régimen laboral en que se encuentre, mantiene vínculo laboral o contractual de cualquier naturaleza con entidades u organismos del Estado, (...), y que en virtud de ello ejerce funciones en dichas entidades u organismos. (Jueces y Fiscales)

\section{Los miembros de las Fuerzas Armadas y Policía Nacional.}

6. Los designados, elegidos o proclamados, por autoridad competente, para desempeñar actividades o funciones en nombre o al servicio del Estado o sus entidades. (Alcaldes)

Los actos de corrupción en los que vienen ocurriendo funcionarios públicos influyen directamente en otras manifestaciones del grupo social. Es el caso, que a través de los medios de comunicación masiva, hemos podido apreciar cómo diferentes grupos humanos afectados por la pandemia han decidido retornar a sus lugares de origen, pues no ven más alternativas de supervivencia en la capital de la república; viéndose obligados a pasar días y noches en las calles, de camino a su pueblo natal (Ojo Público: 14/05/2020). Frente a esta situación, si bien se ha dispuesto por el gobierno central el traslado por razones humanitarias (Decreto Supremo 068-2020-PCM), se puede constatar que poco o nada se ha venido haciendo por parte de las autoridades administrativas, pues hasta estos últimos días continúan retornando informalmente y sin ninguna prueba médica que evite o disminuya el riesgo de contagio a sus conciudadanos.

Lo señalado precedentemente, sumado a las prácticas de corrupción e impunidad que flagelan a nuestra sociedad, tal como lo advierte la Comisión Interamericana de Derechos Humanos, dificultan severamente adoptar medidas efectivas que permitan paliar los efectos perniciosos de la pandemia, siendo las personas de especial vulnerabilidad las que terminan soportando las consecuencias de la misma por un deficiente accionar del Estado, al que se suma no pocas veces un alto grado de indiferencia.

Como se ha anotado, la corrupción es un fenómeno transversal que también agrava la crisis pandémica, pues si ya existen profundas brechas sociales en que la pobreza y la pobreza extrema le configuran un grave problema a todos los Estados, así como la falta o precariedad en el acceso al agua potable y al saneamiento, la inseguridad alimentaria, entre otras; nuestra región se caracteriza por altos índices de violencia generalizada y especialmente violencia por razones de género, de raza o etnia; así como la persistencia de flagelos tales como la corrupción y la impunidad, según lo señala la propia Comisión Interamericana de Derechos Humanos; por lo que, ha recomendado lo siguiente:

Asegurar la existencia de mecanismos de rendición de cuentas y acceso a la justicia ante posibles violaciones de los derechos humanos, incluidos los DESCA, en el contexto de las pandemias y sus consecuencias, incluyendo abusos por parte de actores privados y actos de corrupción o captura del Estado en perjuicio de los derechos humanos.

derechos fundamentales, especialmente ahí donde estas amenazas exigen al Estado un especial deber objetivo de protección. De esta forma el autor concluye que el reconocimiento de un derecho a la protección frente a la corrupción o a vivir en una sociedad libre de corrupción se presenta ahora como una alternativa necesaria y válida. La lucha para hacer frente a la corrupción no es sino la lucha por los derechos fundamentales. 
Por ello, la pandemia exige de los Estados una actuación efectiva y consciente, de manera que se puedan reducir los efectos catastróficos de la enfermedad; y ello supone una actuación que priorice los intereses generales y la dignidad de la persona humana y no los intereses particulares. Tal actuación no podría concretarse si persisten estas prácticas corruptas que se alejan de los verdaderos roles del Estado.

En ese orden de ideas, se debe precisar que la corrupción es un cáncer que se ha expandido en gran parte de los países de América Latina. Así tenemos que mencionar por ejemplo el paralelo que de la misma hace Alfonso Quiroz en su multicitada obra:

A partir de la década de 1980 el retorno a la democracia, tanto en España como en la mayoría de países latinoamericanos, introdujo cambios en las formas de corrupción producidas por los poderes ejecutivos que dominaban a los poderes legislativo y judicial. El mundo ha sido testigo de algunos intentos efectuados por partidos y dirigentes partidarios sedientos de fondos por consolidar ganancias políticas indebidas y recompensar a los colaboradores cercanos (a través de "empresas" partidarias ad hoc y de fondos electorales ilegales). Este fue el caso del Partido Socialista Español en el decenio de 1980; los gobiernos de Fernando Collor de Mello en el Brasil, de Carlos Andrés Pérez en Venezuela, de Carlos Saúl Menem en Argentina, de Carlos Salinas en México, de Arnoldo Alemán en Nicaragua y de Alan García Pérez y Alberto Fujimori en el Perú; y los casos recientemente hechos públicos del régimen de Hugo Chávez en Venezuela y del Partido de los Trabajadores de Luis Inácio Lula da Silva en el Brasil. La corrupción personal de altos funcionarios solamente es la parte más visible y a veces espectacular del problema. En un contexto de liberalización económica y democratización, la nueva corrupción no representa un fenómeno transitorio sino, más bien, otro ejemplo histórico de la capacidad de adaptación de un fenómeno persistente y estructural bajo nuevas transgresiones institucionales, que tienden a inclinar el equilibrio nuevamente hacia el poder presidencial ilimitado. (2016: 39,40).

\section{POBREZA, CORRUPCIÓN Y PANDEMIA}

Por pobreza, se entiende la cualidad de pobre. Hace referencia a las personas que no tienen lo necesario para vivir dignamente, que son humildes o que son desdichadas. La pobreza, por lo tanto, es una forma de vida que aparece cuando las personas carecen de los recursos necesarios para satisfacer sus necesidades básicas. Esta condición se caracteriza por deficiencias en la alimentación, por la falta de acceso a la asistencia sanitaria y a la educación, y por no poseer una vivienda que reúna los requisitos básicos para desarrollarse correctamente. ${ }^{8}$

La pobreza constituye uno de los problemas más importantes cuya erradicación debe priorizar todo Estado social y democrático de derecho, pues es una de las principales brechas de desigualdad en el mundo entero, tal como lo sostiene la propia Comisión Interamericana de Derechos Humanos:

Las Américas es la región más desigual del planeta, caracterizada por profundas brechas sociales en que la pobreza y la pobreza extrema constituyen un problema transversal a todos los Estados.

Su impacto en la sociedad trae como consecuencia la imposibilidad de que las personas o grupos de personas en situación de pobreza puedan ejercer plenamente sus derechos fundamentales; por ello, como se ha anotado, es uno de los problemas más importantes que preocupa a todo Estado. Con acierto Malem Seña ha sostenido lo siguiente:

8 https://definicion.de/pobreza/ (Recuperado: 22/05/2020) 
La pobreza constituye una cuestión que interroga nuestras posiciones desde diversos puntos de vista: moral, político, económico y social. Nada como la pobreza ha de preocupar tanto a los diseños institucionales y a las prioridades políticas, ya que su presencia y la necesidad de su erradicación nos afectan, simplemente como seres humanos. Su impacto negativo concierne a todos los ámbitos de nuestras vidas, en lo personal y lo social (2018: 15-29)9

Nuestro país, también padece del flagelo de la pobreza y lamentablemente las políticas públicas diseñadas por el Estado no han logrado reducir considerablemente los índices de pobreza; tal como lo podemos observar en el siguiente cuadro ${ }^{10}$ :

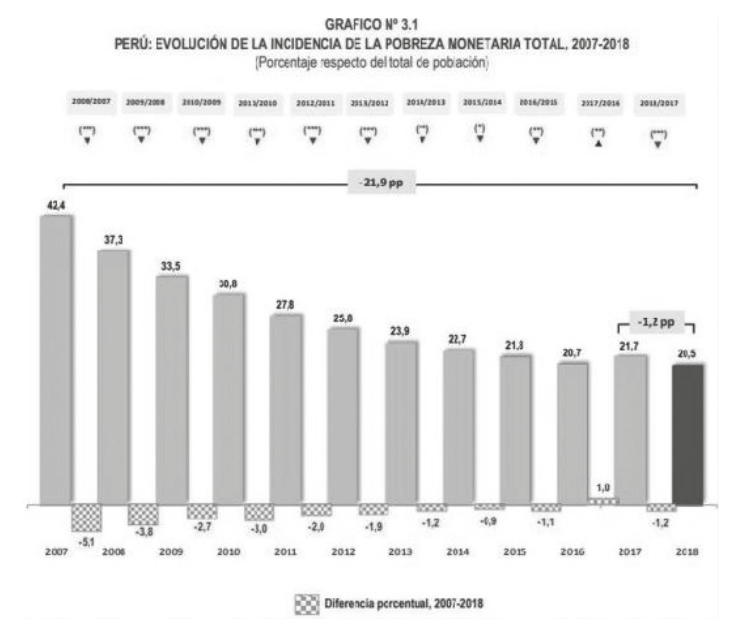

Como se puede observar, la reducción de la pobreza en el país no ha tenido un avance alentador, desde que se advierte que en el año 2018 se tuvo una mínima diferencia porcentual de un $-1.2 \%$ con relación al año $2017^{11}$. En ese sentido, con los índices de pobreza que registra nuestro país resultará imposible el cumplimiento de los fines del Estado democrático, pues existen grupos sociales que atraviesan muchas carencias como hambre, un adecuado sistema de salud, entre otros:

Los pobres suelen carecer, asimismo, de acceso a un sistema de salud integral y gratuito. Y no sólo respecto de enfermedades físicas o biológicas, sino también de enfermedades mentales. Las enfermedades infeccionas, evitables o curables con los medios adecuados actualmente disponibles, las esquizofrenias y el alcoholismo, por hacer referencia solo a tres afecciones comunes, parecen ensañarse con los pobres. Es común constatar, además, que los menesterosos no pueden vivir en condiciones de salubridad mínimamente dignas. La falta de agua potable o de saneamientos adecuados en sus míseras viviendas o barrios no suele $\mathrm{n}$ ser excepcional. (Seña, 2018 p.15-29)

9 Agrega Malem Seña que: la pobreza no se ciñe solo a la carencia de bienes materiales. La identificación de la pobreza únicamente con la posesión o carencia de bienes materiales nos permite comprender todo lo que conlleva. La pobreza afecta a las personas desde vértices muy diferentes. Por esa razón, para el análisis de este fenómeno es necesario un acercamiento multidimensional que supere los ya clásicos métodos de conceptualizarla o medirla a través de la línea de la pobreza o de las necesidades básicas insatisfechas.

En el ámbito político, los pobres son fácilmente manipulados. Con harta frecuencia, en América Latina son virtualmente "acarreados", esto es, llevados en carros, camiones o autobuses, a los actos políticos u obligados a vender su voto bajo la amenaza de pérdida de subsidio si lo poseen, de su trabajo o, en casos extremos, de su vida. Sus intereses son poco tenidos en cuenta, ya que no suelen tener representantes idóneos que apliquen sus votos o instancias que hagan valer sus pretensiones. En algunos países de lberoamérica, la política democrática parece estar pensada para otro tipo de personas.

$10 \mathrm{https}$ ://elcomercio.pe/economia/peru/pobreza-monetaria-pobreza-extrema-peru-disminuyo-2018-noticia625267-noticia/?ref=ecr

11 En el año 2019 , el índice de pobreza monetaria afectó al $20.2 \%$ de la población del país, con lo cual mantiene prácticamente los mismos niveles del año 2018, cuando la pobreza alcanzó al $20.5 \%$ de la población, reportó hoy el Instituto Nacional de Estadística e Informática (INEI) según los resultados de la Encuesta Nacional de Hogares (ENAHO) del año 2019. (En Gestión: URL: https://gestion.pe/peru/nivel-de- pobreza-en-peru-se-redujo-ligeramenteen-el-2019-noticia/ Recuperado el 21/05/2020) 
En ese orden de ideas podemos señalar que la pobreza tiene consecuencias negativas que afectan a varios derechos fundamentales; por ejemplo, la violación del derecho a la salud es consecuencia de la pobreza; a su vez, la afectación de dicho derecho es causa de la pobreza. Esta condición genera una situación circular de causa y efecto; así, las violaciones de varios derechos como a la salud, a la pensión alimenticia y a una educación de calidad, entre otros, son causa y efecto de la pobreza, tal como lo ha entendido Malem Seña:

La pobreza, sobre todo si es extrema, produce hambre. El hambre se ceba en los niños que padecen mal nutrición desde el momento mismo de la concepción. La desnutrición infantil de niños menores de cinco años genera riesgo de muerte, inhibe su desarrollo cognitivo y afecta su salud de por vida. Sufrir hambre durante el periodo de la infancia puede provocar retrasos elementales irreversibles y una disminución del coeficiente de inteligencia. El hambre dificulta el aprendizaje y aleja al niño de los centros educativos. Es fuente de enfermedades, que se suelen hacer crónicas, y es causa de exclusión social. Y crea las condiciones para que el hambriento no pueda superar su situación. Esto supone a la vez, como si se tratara de un caso de circularidad causal, que el hambre es causa y consecuencia de la pobreza. (Seña, 2018 p.15-29)

Pero ahí no acaba todo. Se ha vuelto un reto casi imposible para los Estados luchar contra la pobreza y pobreza extrema; mucho menos radicalizarla, sobre todo en países subdesarrollados como el nuestro que no han tenido resultados alentadores en la lucha contra dichas condiciones, tal como se ha visto líneas arriba. Asimismo, la pobreza no sólo puede ser entendida como una causa para las catástrofes, sino que tiene también una incidencia fuerte en la falta de habilidad para recobrarse de una que ya haya ocurrido (Súmar, 2011 p.285-303). En ese sentido, frente a la actual situación de pandemia por el COVID-19 que azota a varios países con altos índices de pobreza como el nuestro, resultará mucho más complicado adoptar políticas idóneas y efectivas para salir o recuperarse de todos los males que ha traído esta pandemia.

La par corrupción-pobreza tiene unos efectos ruinosos sobre la vida de las personas. Según los índices de Transparencia Internacional, los países con índices más altos de corrupción poseen, a su vez, mayores bolsones de pobreza, o son simplemente pobres (Seña 2018: 15-29). De esta forma, corrupción y pobreza tienen una relación estrecha, y esto devendrá inevitablemente en la afectación de los derechos fundamentales con el derecho a la salud. Y es que, la corrupción afecta también a la democracia, esto es, a la idea de que todos somos iguales ante la ley y que toda decisión que se tome en las esferas de poder deber hacerlo con respeto por los derechos e intereses de los ciudadanos; pero una sociedad con alta dosis de corrupción tal situación no ocurre, de manera que hay menos democracia. (Seña 2018: 15-29)

Finalmente, llegamos a la conclusión de que la pobreza y el fenómeno de la corrupción son causa y consecuencia de las violaciones de los derechos humanos; por ello, en una situación de pandemia el derecho a la salud y otros derechos no se encuentran plenamente garantizados. A la corrupción, pobreza y violación de derechos humanos hay que entenderlas como auténticas calamidades humanas y no como catástrofes provocadas por agentes incontrolables; son tres males en sí mismo considerado y cuando operan conjuntamente generan efectos infaustos (Seña 2018: 15-29). Y es el ciudadano de a pie quien sufre las consecuencias de dichos males; son los que más pierden por su condición de pobreza y por las prácticas de corrupción que flagela a nuestro país, y cada vez ven con menos esperanzas un sistema de salud adecuado y el respeto de sus derechos.

\section{TRABAS BUROCRÁTICAS EN EL TRASLADO POR RAZONES HUMANITARIAS}

Mediante Decreto Supremo N. ${ }^{\circ}$ 068-2020-PCM, publicado el 14 de abril de 2020 en el Diario Oficial El Peruano, se autorizó de manera excepcional, por razones humanitarias y previa coordinación con 
el gobierno regional que corresponda, el transporte interprovincial de pasajeros, por medio terrestre y aéreo no comercial, que se encuentren fuera de su residencia o lugar de trabajo habitual, a consecuencia de la aplicación de las disposiciones de inmovilización social. Asimismo, se dispuso que, en todos los casos se deba, garantizar que se cumplan las condiciones de salud y seguridad establecidas para su traslado y el aislamiento social obligatorio correspondiente en los lugares de destino.

Los hechos que motivaron la disposición decretada consistieron en que, en pleno Estado de Emergencia, cientos de ciudadanos de diversas regiones del país empezaron a movilizarse hacia el lugar de su residencia o trabajo habitual, pese a la orden de inmovilización decretada con anterioridad a nivel nacional. Personas sin trabajo y sin otra fuente de ingresos económicos, es decir, sin oportunidades de supervivencia, no vieron más alternativa que migrar a su lugar de origen en busca de nuevas formas de sobrevivir ante la crisis pandémica.

Si bien el Estado reaccionó ante tal situación y muchos han logrado beneficiarse con el traslado humanitario (El Peruano: 19/05/2020), lo cierto es que, en realidad, no se ha visto efectividad de parte de los gobiernos regionales ni locales para adoptar medidas oportunas y efectivas que concreten el traslado humanitario de quienes aún se encuentran en situación de vulnerabilidad. Y es que, mucho después de la disposición del traslado decretada por el gobierno, se sigue observando que cientos de personas continúan tratando de salir de la ciudad a su lugar de origen, evadiendo los controles policiales y protocolos sanitarios, tal vez al no ver más alternativa y ante poca actuación de las autoridades correspondientes, pues esa es la percepción que uno puede abstraer luego de haber sido testigo en el mismo lugar mencionado.

Es importante advertir la existencia de una serie de trabas burocráticas que dificultan el cumplimiento de los fines que deben vincular a los gobiernos locales o regionales; la existencia de dichas trabas o costos administrativos pueden ser un impedimento para el desarrollo, sobre todo de los más pobres (Súmar 2011: 294); más aún en una situación de pandemia donde urge adoptar medidas urgentes y efectivas para salvaguardar la integridad de las personas. Creemos que toda forma de trabajo que priorice las formalidades excesivas para la toma de decisiones en relación a la protección de las personas, no se condice con un Estado democrático de derecho, conforme lo consagra el artículo 43 de la constitución; todo lo contrario, implicaría un retroceso a las formas de estados decimonónicos en perjuicio de la persona humana.

\section{TOLERANCIA CERO EN LA LUCHA CONTRA LA CORRUPCIÓN}

Si nuestras autoridades no aplican correctamente las normas y prefieren optar por el camino de lo torcido, nos encontramos en un serio problema. El gobierno del presidente Vizcarra ha emprendido una lucha frontal contra la corrupción. La "tolerancia cero" es un concepto que nos hemos prestado de la jerga policial norteamericana. Leyes sobran. El problema los agentes que operan sobre las mismas. Cuenta la tradición, que alguna vez cuando fue preguntado don Ricardo Palma sobre qué ley era necesaria para que todo mejorase y, en forma alguna, se pueda decir que el país caminase sobre ruedas, su respuesta fue tan simple como genial. Solamente hace falta que se promulgue una ley: una que señale que se cumplan todas las anteriores.

Una frase muy trillada es aquella que señala: "roba, pero hace obras". Se siente rabia ajena al ver como autoridades municipales se apropian de alimentos de primera necesidad destinados a personas de escasos recursos económicos; o que de repente se produzca un hecho más grave: que los beneficiados sean personas de buen pasar, y que no requieren de los mismos.

En una tesis presentada para optar el grado de Maestra en Derecho Constitucional señala lo siguiente: 
La corrupción es una violación a los derechos fundamentales de las personas porque impide que estas ejerzan sus derechos y vivan con dignidad, el dinero sustraído estaba destinado a obras como vacunas para niños, construcción de hospitales, construcción de carreteras, construcción de escuelas y muchas otras obras de las cuales nunca gozaron los destinatarios finales. (Miranda, 2012).

Otro triste espectáculo es el que han brindado altos oficiales de la Policía Nacional del Perú al comprar a precios sobrevalorados mascarillas y otros productos que se usan en la lucha contra la pandemia y que no reúnen las especificaciones técnicas necesarias para poder ser empleados en este combate frontal. Según la tesis que maneja el Ministerio Público los policías involucrados han contratado a una empresa que no contaba con las autorizaciones correspondientes del Ministerio de Salud (Minsa). Mientras por un lado existen valerosos policías que arriesgan sus vidas tratando que se respete el orden social y las medidas de seguridad que se deben mantener para reducir el contagio del virus, por el otro sus camaradas de armas se desviven por engrosar sus cuentas bancarias.

\section{CONCLUSIONES}

Muy a pesar del gravísimo problema epidémico que nos aqueja, algunos funcionarios públicos haciendo tabla rasa del colapso del sistema económico-financiero, que afecta principalmente a la población más necesitada, han encontrado terreno fértil para lucrar sin importarles la situación, y en el caso de los oficiales de la Policía Nacional del Perú si sus colegas pierdan la vida como consecuencia de sus acciones, lo que de modo similar ocurre con los alcaldes que privan a la población objetiva de alimentos de primera necesidad, atentando directamente contra su salud, pudiendo como consecuencia de dicho accionar presentarse resultados de pérdida de vidas humanas.

Como consecuencia de lo expuesto precedentemente, si bien es cierto que el Poder Ejecutivo se ha visto en la imperiosa necesidad de implementar un plan de Tolerancia Cero contra este tipo de conductas, afrontando una lucha contra la corrupción, consideramos que se hace necesaria la participación ciudadana, como un primer mecanismo de control, a través de canales de comunicación (p. ej.: líneas telefónicas), y que una vez recibida la denuncia (con una obvia reserva de datos personales), se constate la información recibida, y de ser veraz, se tomen los correctivos inmediatos.

Los gobiernos regionales y locales no han tenido la habilidad suficiente, o al menos razonable, para enfrentar de manera idónea la situación de miles de ciudadanos o pobladores en el retorno a sus lugares de origen, a quienes no ha podido sacarles de encima las trabas administrativas que imperan en el sistema, afectando el derecho de miles de ciudadanos en el traslado humanitario dispuesto por el gobierno. No se ha implementado un protocolo para el traslado de masas humanas que por su cantidad y el aglomeramiento eran candidatas potenciales a contagiarse con el coronavirus.

La corrupción se encuentra enquistada en nuestro país desde el tardío periodo colonial, y en la actualidad en plena pandemia provocada por el COVID-19, se vienen realizando prácticas corruptas en todas las instancias de poder, en desmedro de la dignidad de la persona humana, que cada vez más ponen en riesgo la salud y sus vidas. A ello se suma la pobreza como una condición que opera junto a la corrupción, agravando cada vez más los derechos e intereses de los ciudadanos.

Una vez terminada la pandemia, debe comenzar una actividad a destajo de tres organismos estatales: la Contraloría General de la República, el Ministerio Público y el Poder Judicial para que una vez hechas las indagaciones preliminares si se encuentran indicios de una probable comisión de los hechos delictivos, se instalen los correspondientes procesos y de encontrarse responsabilidad penal, se les aplique a los funcionarios responsables todo el peso de la ley. 


\section{JURISPRUDENCIA RELEVANTE}

En el contexto que nos ocupa, podemos referir algunas resoluciones judiciales que guardan relación con el tema materia de investigación:

Diferencia entre apropiación ilícita y peculado:

Para que se configure el delito de Apropiación llícita, previsto y sancionado en el artículo ciento noventa del Código Penal, es requisito sine qua non que el sujeto activo (cualquier persona) haya entrado en posesión del bien apropiado con la obligación de su posterior entrega. En cambio, en el delito de peculado para que se configure la conducta típica de dicho delito se requiere que el agente (funcionario o servidor público) se apropie o utilice de caudales o efectos que se encuentran bajo su administración o custodia (Ejecutoria Suprema del 01/04/2003, Exp. N 864-2002, Ancash. En: SALAZAR SÁNCHEZ, N. (2004). Delitos contra la Administración Pública (Jurisprudencia Penal). Jurista Editores. Lima, pp. 37 y 229).

Conducta típica en el peculado: "Las pruebas actuadas durante el proceso conducen a la convicción de la responsabilidad penal de los acusados (...) quienes en contubernio se apropiaron de la suma de dinero (...) correspondiente al pago del impuesto por limpieza pública, parques y jardines (...)". (Ejecutoria Suprema del 14/10/2002, Exp. N4252-2001, Lima. En: SALAZAR SÁNCHEZ, N. (2004). Delitos contra la Administración Pública (Jurisprudencia Penal). Jurista Editores. Lima, pp. 38 y 244$)$.

Naturaleza jurídica del cohecho pasivo propio:

Se entiende por cohecho pasivo propio, la conducta del funcionario que solicita o acepta una dádiva (en sentido amplio) o promesa para realizar un acto al margen de la ley en la esfera de su competencia. Las modalidades del cohecho pasivo propio se distinguen por el acto del funcionario en el ejercicio de su cargo (...). El supuesto más grave es aquel en el que la dádiva se pre-ordena a una acción u omisión constitutiva de delito. La segunda modalidad se produce cuando la dádiva se preordena a la realización por el funcionario de un acto injusto relativo al ejercicio de su cargo (...). (Díaz y García, M.1997,pp.162 y 164.)

Conducta típica en el cohecho pasivo propio:

Cabe precisar que para la norma sustantiva, resulta irrelevante el destino que el sujeto activo pretenda otorgar al dinero obtenido mediante un acto de corrupción, incluso puede tratarse de buscar un beneficio personal o de terceros, por ello lo esbozado por el encausado, al aducir que se trataba de un donativo cuya finalidad era apoyar la candidatura política de su esposa no lo exime, por cuanto el cohecho pasivo propio se funda en el quiebre de su integridad, en la transgresión a los dictados de su función, situación que se manifiesta cuando este solicita la ventaja pecuniaria bajo el ofrecimiento de no investigar actos irregulares de la Caja de Pensiones Militar y Policial, lo que implicaba un recíproco intercambio de prestaciones en quebrantamiento de su mandato como congresista" (Ejecutoria Suprema del 23/07/2003, R.N. N 11-2001, Lima. En: Pérez, M. (2006). La evolución de la jurisprudencia en el Perú (20012005). Tomo II, luris Consulti. Editorial San Marcos, Lima, p.1511).

\section{REFERENCIAS}

- Basadre, J. (1969) Historia de la República del Perú. Lima, Perú. Ediciones Universitarias.

- Belaunde, V. (2014) El Expediente Prado. Primera edición. Lima, Perú: Universidad San Martin de Porres. 
- Brioschi, C. (2019) Breve Historia de la Corrupción. De la antigüedad a nuestros días. Madrid, España: Penguim Random House Grupo Editorial España.

- Colchado, G. (15 de mayo de 2020) Héroes de la salud: cada 12 horas murió un médico por Covid-19 este mes. Recuperado de: https://elcomercio.pe/lima/sucesos/ coronavirus- peru.heroes.de.la.salud.cada-12-horas-murio-un-medico-por-covid-19-estemes-noticia/?ref=ecr

- Díaz, M. (1997) El delito del tráfico de influencias en: Asúa Batarrita (Ed.): Delitos contra la Administración Pública. Bilbao, España: Instituto Vasco de Administración Pública.

- García, E., "Lucha contra la corrupción y derechos fundamentales en el Perú: ¿transitar del principio constitucional de proscripción de la corrupción a un derecho fundamental a vivir libres de corrupción?" En Derechos Fundamentales. Actas de las III Jornadas Nacionales de Derechos Fundamentales; Lima Palestra; pp. 33 - 47

- León, J. (2019), "Protección frente a la corrupción o vivir en una sociedad libre de corrupción: ¿un nuevo derecho fundamental?" En Derechos Fundamentales. Actas de las IV Jornadas Nacionales de Derechos Fundamentales; Lima Palestra; pp. 59 - 70

- Lovatón D. y Indacochea, U. (2019), "Sistema interamericano, independencia judicial y corrupción" En Derechos Fundamentales. Actas de IV las Jornadas Nacionales de Derechos Fundamentales; Lima Palestra; pp. 71 - 75

- Malem, J. (2018), “Corrupción, pobreza y Derechos Humanos?” En Derechos Fundamentales. Actas de las III Jornadas Nacionales de Derechos Fundamentales; Lima Palestra; pp. 59 - 70

- Miranda, M.A. (2012) Proyecto de innovación profesional. "Política nacional de transparencia y lucha contra la corrupción" (Tesis para optar el grado de maestra en Derecho Constitucional). Universidad andina Simón Bolívar, La Paz, Bolivia. Recuperada de http:// repositorio.uasb. edu.bo/handle/54000/411.

- Nieto, A. (2013) La privatización de la lucha contra la corrupción. Huelva, España: Repositorio Institucional de la Universidad de Huelva.

- Olano, H. (2017) ¿Dónde está la transparencia? Reflexión sobre la corrupción. Chía, Colombia: Recursos Educativos Digitales Abiertos. Universidad de La Sabana.

- Pérez. M. (2006) La evolución de la jurisprudencia en el Perú. (2001-2005). Tomo II. Lima, Perú. Editorial San Marcos.

- Quiroz,A. (2016) La Historia de la Corrupción en el Perú, 2da. Edición, Lima, IEP, 2013.

- Resolución N 1/2020, de la Comisión Interamericana de Derechos Humanos. Pandemia y Derechos Humanos en las Américas.

- Salazar, N. (2004) Delitos contra la Administración Pública. Jurisprudencia Penal. Lima, Perú: Jurista Editores.

- Sumar, O. (2011), "La pobreza como desastre". En El Derecho frente a la pobreza. Los desafíos éticos del constitucionalismo de los derechos. Lima, Palestra, pp. $285-303$.

- Urquizo, J. (2016) Código Penal Práctico. Concordancias/Doctrina/Jurisprudencia/Evolución Legislativa. Tomo II. Lima, Perú: Gaceta Jurídica.

\section{Otras fuentes:}

\section{Tomado de internet:}

- https://ojo-publico.com/1786/desplazados-por-la-pandemia-la-travesia-de-los-mas-pobres

- https://elperuano.pe/noticia-traslado-humanitario-24606-personas-pudieron-retornar-a-suslugares- origen-por-emergencia-96020.aspx

- https://gestion.pe/peru/coronavirus-peru-ministerio-publico-investiga-76-casos-de-presuntacorrupcion-en-estado-de-emergencia-covid-19-estado-de-emergencia-nndc-noticia/

- https://larepublica.pe/sociedad/2020/04/01/familias-reciben-alimento-vencido-del-gobiernode- tumbes-pobreza-cuarentena-coronavirus-Irnd/ 
- https://www.prensaregional.pe/region-arequipa/islay/cocachacra/entregan-azucar-vencidaen- canastas-del-municipio-de-cocachacra/

- https://gestion.pe/peru/peru-es-el-tercer-pais-que-se-percibe-como-el-mas-corrupto-deamerica- latina-según-transparencia-internacional-noticia/?ref=gesr

Fecha de recepción: 22 de mayo de 2020

Fecha de aceptación: 01 de junio de 2020 